Research Article

\title{
Calculation of the Neutron Parameters for Accelerator-Driven Subcritical Reactors
}

\author{
Tien Tran Minh ${ }^{1}{ }^{1}$ and Dung Tran Quoc ${ }^{2}$ \\ ${ }^{1}$ Thu Dau Mot University, Thu Dau Mot, Binh Duong Province, Vietnam \\ ${ }^{2}$ Center for Nuclear Techniques, Ho Chi Minh City, Vietnam \\ Correspondence should be addressed to Tien Tran Minh; tientm@tdmu.edu.vn
}

Received 20 May 2021; Revised 23 July 2021; Accepted 2 December 2021; Published 20 December 2021

Academic Editor: Arkady Serikov

Copyright (c) 2021 Tien Tran Minh and Dung Tran Quoc. This is an open access article distributed under the Creative Commons Attribution License, which permits unrestricted use, distribution, and reproduction in any medium, provided the original work is properly cited.

\begin{abstract}
In this paper, the accelerator-driven subcritical reactor (ADSR) is simulated based on structure of the TRIGA-Mark II reactor. A proton beam is accelerated and interacts on the lead target. Two cases of using lead are considered here: firstly, solid lead is referred to as spallation neutron target and water as the coolant; secondly, molten lead is considered both as a target and as a coolant. The proton beam in the energy range from $115 \mathrm{MeV}$ to $2000 \mathrm{MeV}$ interacts with the lead to create neutrons. The neutron parameters as neutron yield $Y_{n / p}$, neutron multiplication factor $k$, the radial and axial distributions of the neutron flux in the core have been calculated by using MCNPX program. The results show that the neutron yield increases as the energies of the proton beam increases. When using the lead target, the differences between the neutron yield are from $4.2 \%$ to $14.2 \%$ depending on the energies of the proton beam. The proportion of uranium in the mixtures should be around $24 \%$ to produce an effective neutron multiplier factor greater than 0.9. The neutron fluxes are much higher than the same calculations for the TRIGA-Mark II reactor model using tungsten target and light water coolant.
\end{abstract}

\section{Introduction}

The accelerator-driven subcritical reactor (ADSR) is a reactor that can generate energy and transmute radioactive wastes cleanly and safely [1]. One of the essential issues for an ADSR is that it must be designed so that it remains subcritical during operation.

For an ADSR, the neutron source used to maintain the operation of ADSR is generated by the interaction of highenergy proton beam with heavy targets, such as lead, tungsten, or a lead-bismuth mixture, as spallation neutron sources. The important parameters related to the design and operation of ADSR as neutron yield, neutron multiplication factor, or distributions of the neutron flux should be considered. ADSR can be fueled with nonenriched thorium, which is four times more abundant than uranium. In ADSR, unlike conventional uranium fuel, thorium is burnt, leaving much less radiotoxic waste and almost no plutonium. Therefore, thorium has a potential to achieve both production of electricity without emitting $\mathrm{CO}_{2}$ and reduction of concerns of ordinary nuclear power fueled by uranium.

There are many recent studies about features and models of the ADSR. Asuncion-Astronomo et al. [2] studied about computational design and characterization of a subcritical reactor assembly with TRIGA fuel. In this paper, the design for subcritical reactor assembly (SRA) with 44 TRIGA fuel rods is proposed. The parameters of SRA were computed by MCNP code. Vega-Carrillo et al. [3] studied about features of a subcritical nuclear reactor. In that study, the $k_{\text {eff }}$ of the Universidad Autonoma de Zacatecas Subcritical Nuclear Reactor (UAZSNR) was calculated using six-factor formula and the Monte Carlo method. The ambient dose equivalents were estimated. Henry et al. [4] analyzed physical parameters of Jozef Stefan Institute (JSI) TRIGA-Mark II reactor with TRIPOLI and MCNP. A new computational model of the JSI TRIGA-Mark II reactor was built for TRIPOLI computer code and compared with existing MCNP code model. The neutron spatial flux profile measurement in compact 
subcritical system using miniature neutron detectors was conducted by Shukla et al. [5]. In that research, the authors presented the thermal neutron flux profile measurement in a compact subcritical system using indigenously developed miniature gas filled neutron detectors. A comparison of measured neutron flux using these detectors and simulated Monte Carlo computations was also given.

The TRIGA-Mark II reactor model is simulated and calculated neutron parameters by the MCNPX program $[6,7]$. The proton beam generated from an accelerator with an intensity of $2 \mathrm{~mA}$ interacts on a tungsten target. A fuel mixture of $\mathrm{UZrH}$ (uranium zirconium hydride) with a $20 \%$ enrichment was considered. $[8,9]$. The use of solid target to generate neutrons and light water as coolant in the ADSR system requires the target to be in a vacuum system and must be replaced after a period of use. To overcome this, molten lead is considered as both a coolant and a spallation neutron target. Preliminary study on this issue has been performed [10].

In this paper, with fuel as $\mathrm{UZrH}$ and UThO, two cases of using lead are considered: firstly, solid lead is referred to as spallation neutron target and water as the coolant; secondly, molten lead is seen as spallation neutron target and as a coolant. The percentages of components of $\mathrm{Pb}-206, \mathrm{~Pb}-207$, and $\mathrm{Pb}-208$ are $25.5 \%, 22.1 \%$, and $52.4 \%$, respectively. The density of solid lead is $11.34 \mathrm{~g} \cdot \mathrm{cm}^{-3}$ and that of molten lead is $10.66 \mathrm{~g} \cdot \mathrm{cm}^{-3}$.

The fuel, a mixture of uranium and thorium in different proportions, is placed in the core reactor, with the different coolants. The proton beam with energies from $115 \mathrm{MeV}$ to $2000 \mathrm{MeV}$, which interacts with the lead targets in solid and molten forms, was used to control the TRIGA-Mark II reactor. The parameters, as neutron yield $Y_{n / p}$, the neutron multiplication factor, and axial and radial distributions of the neutron flux along with the core, are investigated. The MCNPX [11] code has been used for the simulation and the calculations.

\section{Materials and Methods}

2.1. The TRIGA-Mark II Reactor Model. The TRIGA-Mark II subcritical reactor model was simulated as shown in Figure 1. Some characteristics of the core are shown in Table 1. The structure of the core consists of 108 fuel rods. The core is divided into 7 rings. All of these are assumed to be placed in the molten lead medium.

The detailed structure of the fuel rod is shown in Figure 2 [8].

2.2. Calculations. MCNPX program has been used to simulate and calculate the neutronic parameters. The input file is constructed based on the detailed configuration of the TRIGA reactor. The neutron yield $\left(Y_{n / p}\right)$ is calculated for the case of the proton beam current $2 \mathrm{~mA}$ interacting on the molten lead target in the core. Two options for distribution of the proton energy were considered for MCNPX code: parabolic spatial and uniform spatial distribution. Some calculations show that the differences between these options are negligible. In this study, the parabolic spatial distribution of the energy of the proton beam is chosen.

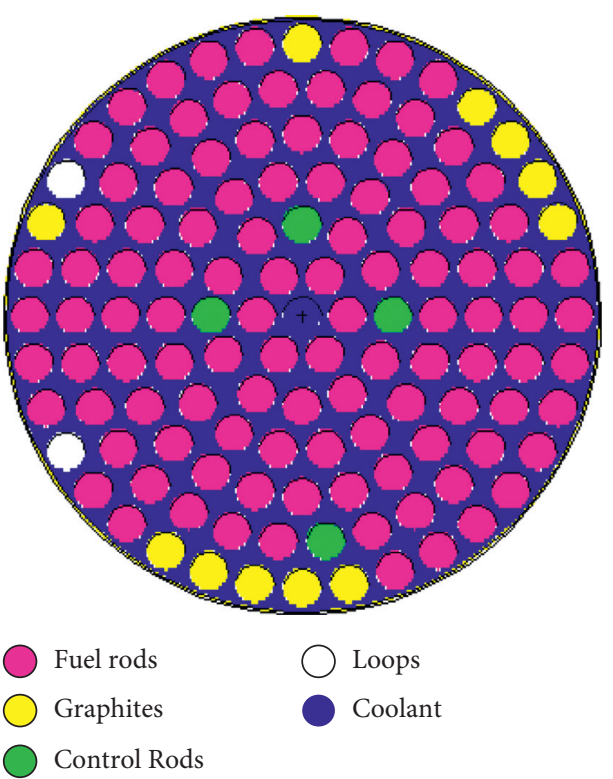

FIgURE 1: View of horizontal cross-section of TRIGA core simulated.

TABLE 1: Structure of TRIGA core.

\begin{tabular}{lc}
\hline Characteristics & Details \\
\hline Fuels & $\mathrm{UZrH}, \mathrm{UThO}$ \\
Density of the fuel & $5.8 \mathrm{~g} \cdot \mathrm{cm}^{-3}, 10.5 \mathrm{~g} \cdot \mathrm{cm}^{-3}$ \\
Coolant & Light water or molten lead \\
Reflectors & Graphite \\
Density of the reflectors & $2.25 \mathrm{~g} \cdot \mathrm{cm}^{-3}$ \\
Control rods & $\mathrm{B}_{4} \mathrm{C}$ \\
Diameter of the fuels & $3.73 \mathrm{~cm}$ \\
Height of the fuels & $38.1 \mathrm{~cm}$ \\
Diameter of the core & $56 \mathrm{~cm}$ \\
Height of the core & $72 \mathrm{~cm}$ \\
\hline
\end{tabular}

The neutron multiplication factor $(k)$ is calculated from KCODE in MCNPX. The neutron flux is calculated from F4 tally in MCNPX based on the following equation:

$$
F 4=C \int(E) R(E) \mathrm{d} E,
$$

with normalization for the current of proton beam $\mathrm{I}(\mathrm{mA})$ and neutron yield $Y_{n / p}$, where $\mathrm{C}$ is a multiplication, $\Phi(E)$ $\left(\mathrm{n} \cdot \mathrm{cm}^{-2} \mathrm{~s}^{-1}\right)$ is the neutron flux, and $R(E)$ is any combination of sums and products of energy-dependent quantities known to MCNPX [8]. The neutron flux has been determined according to the following equation [5]:

$$
\Phi=\frac{2 \times 10^{-3} \mathrm{C} / s}{m A} \times \frac{1 p}{1.6 \times 10^{-19} \mathrm{C}} \times F 4 \times Y_{n / p},
$$

with $Y_{n / p}(n / p)$ being the neutron yield.

\section{Results and Discussion}

3.1. Neutron Yield $Y_{n / P}$. The neutron yield $Y_{n / p}$ is the average number of neutrons produced per incident proton. In this investigation, proton beams with energies between $115 \mathrm{MeV}$ 


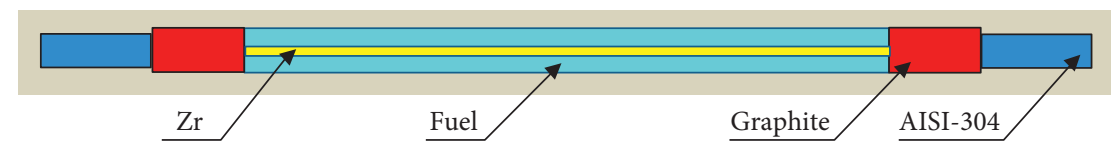

Figure 2: The detailed structure of the fuel rod.

and $2000 \mathrm{MeV}$ were considered as the source of neutrons when they interact with lead target. Energy cross-section data from file nuclear data ENDF/B-VII.0 [12] were used. The results are shown in Table 2.

The results show that for the fixed proton current $(2 \mathrm{~mA})$, the neutron yields increase as energies of the incident proton beam increase. When using the lead target, the neutron yield is from 0.477 to 24.211 depending on the energies of the proton beam.

In comparison with the calculation results of references [7-9], the neutron yield of the lead target was about $4.2 \%$ higher than that of tungsten at an energy level of $115 \mathrm{MeV}$. However, the value of $Y_{n / p}$ decreased by $14.2 \%, 8.2 \%$, and $2.9 \%$, respectively, corresponding to the energy of the proton beam of $300 \mathrm{MeV}, 600 \mathrm{MeV}$, and $1000 \mathrm{MeV}$. These insignificant differences suggest that lead can be used as a suitable target to generate neutrons for ADSR.

3.2. Neutron Multiplication Factor $K$. The $k$ factor is calculated for fuel mixtures of uranium and thorium with different ratios. For TRIGA reactor, the previous studies [8] investigated the case of the $\mathrm{UZrH}$ (uranium zirconium hydride) fuel placed in the light water. In this paper, besides calculating for the fuel $\mathrm{UZrH}$, the fuel mixture thoriumuranium oxide (ThUO) was also considered. Details of the ratio of components in the fuel mixture and calculation results of $k$ have been presented in Table 3 .

The results have been shown that for UZrH mixed fuel, the higher the ratio of uranium in the mixture, the higher the $k$. Let the $k$ reach to the values higher than 0.9 , then the proportion of uranium in the mixture must be greater than $24 \%$. For ThUO mixture fuel, the results show a correlation between Th-232 and U-233 in fuel composition. As the component ratio U-233 increases, the $k$ coefficient also increases. The parameter $k$ reaches a value greater than 0.9 when U-233 accounts for about $29 \%$ of the mixture.

3.3. Distributions of the Neutron Flux. On the basis of fuel composition data of UZrH and ThUO fuel given in Table 3, the neutron flux distributions on the height and the radius of the core with the light water coolant were calculated.

\subsubsection{The Case of UZrH Fuel and Light Water Coolant.} The neutron flux distributions have been calculated for the case of the mixture of $\mathrm{UZrH}$ fuel, placed in light water, similar to the calculated models given in the previous studies [7-9]. To compare the neutron flux distribution as using solid lead and solid tungsten target, the differences of the neutron yield are considered. The axial distributions of the neutron flux have been calculated. These results are shown in Figure 3.
The results show that, with the same neutron multiplication factor, neutron flux distributions depend on the neutron yields. They depend on the properties of the target with the reactions of spallation and (p, n). Calculation results show that the neutron yield of solid lead is higher than that of tungsten. With $k=0.91$, the maximum neutron flux is about $2.8 \times 10^{13} \mathrm{n} \cdot \mathrm{cm}^{-2} \mathrm{~s}^{-1}$ for a solid lead target and from $1.3 \times 10^{13}$ to $1.4 \times 10^{13} \mathrm{n} \cdot \mathrm{cm}^{-2} \mathrm{~s}^{-1}$ for a tungsten target, as shown in the previous studies [7-9]. For case of $k=0.97$, the maximum neutron flux is about $1.6 \times 10^{13} \mathrm{n} \cdot \mathrm{cm}^{-2} \mathrm{~s}^{-1}$, compared with about $7.5 \times 10^{12}$ to $7.6 \times 10^{12} \mathrm{n} \cdot \mathrm{cm}^{-2} \mathrm{~s}^{-1}$ for a tungsten target.

\subsubsection{The Case of UZrH Fuel and Molten Lead Coolant.}

The calculation of neutron flux along the height of the core with the UZrH mixture fuel placed in molten lead as target and coolant is already underway. Results are shown in Figure 4. The maximum and minimum values of neutron flux calculated by this work and previous publications are given in Table 4.

Results show that the neutron flux along the height of the core was maximum in the center and decreased to the core edge. The results in Table 4 show that with the same $k$ value, the neutron flux of the fuel configuration $\mathrm{UZrH}$ in molten lead as the coolant and spallation neutron target (Case 1) has the highest value. The lowest value of the neutron flux belongs to the fuel profile $\mathrm{UZrH}$ in light water and the neutron generated by the tungsten target (Case 3). For $k$ equal to 0.91 and 0.97 , the neutron flux in Case 1 is about 8-11 and 6-9 times greater than in Case 3, respectively. The maximum-to-minimum ratio of neutron flux also shows that neutron flux in Case 1 is more uniform than in the other cases. Results in Case 2 also show that solid lead could be used as spallation neutron target for UZrH fuel immersed in light water.

\subsubsection{The Case of ThUO Fuel and Molten Lead Coolant.} The composition ratios of ThUO fuel are given in Table 3. The axial and radial distributions of the neutron flux have been calculated for ThUO fuel placed in the molten lead. The results in Figure 5 show that the axial distribution of the neutron flux is symmetrical at the center of fuel pin and peaks at that position.

Results of the calculation of the radial distribution of the neutron flux are given in Table 5 and Figure 6 . These results differ from the published results [6-8]. The neutron fluxes in this study peak at a position of about $3-5 \mathrm{~cm}$ along the radius from the center of the reactor core, while they are in the $8-10 \mathrm{~cm}$ range as shown in the references. The results also show that, compared with the reference results [6-8], the value of the maximum flux in this study is about 4.8 and 3.7 
TABLE 2: The neutron yields for two targets (solid and molten lead) used.

\begin{tabular}{lcc}
\hline Energy $(\mathrm{MeV})$ & $Y_{n / p}$ (this work, lead target) & $Y_{n / p}$ (Hassanzadeh et al, tungsten) \\
\hline 115 & 0.477 & 0.464 \\
300 & 2.631 & 2.984 \\
600 & 7.181 & 7.773 \\
1000 & 13.072 & 13.450 \\
1200 & 15.732 & - \\
1400 & 18.187 & - \\
1600 & 20.207 & - \\
1800 & 22.359 & - \\
2000 & 24.211 & - \\
\hline
\end{tabular}

Table 3: Details of the ratio of components in the fuel mixture and calculation results of $\mathrm{k}$.

\begin{tabular}{|c|c|c|c|c|c|c|c|c|}
\hline & ${ }_{90}^{232} \mathrm{Th}$ & ${ }_{92}^{233} U$ & ${ }_{92}^{235} \mathrm{U}$ & ${ }_{92}^{238} \mathrm{U}$ & $\begin{array}{l}91 \\
40\end{array}$ & ${ }_{1}^{1} \mathrm{H}$ & ${ }_{8}^{16} \mathrm{O}$ & $k$ \\
\hline \multirow{6}{*}{ UZrH mixture } & - & - & 0.0400 & 0.1600 & 0.300 & 0.500 & - & 0.81088 \\
\hline & - & - & 0.0440 & 0.1760 & 0.300 & 0.480 & - & 0.87406 \\
\hline & - & - & 0.0452 & 0.1808 & 0.294 & 0.480 & - & 0.88656 \\
\hline & - & - & 0.0480 & 0.1920 & 0.292 & 0.468 & - & 0.92804 \\
\hline & - & - & 0.0492 & 0.1968 & 0.290 & 0.464 & - & 0.94203 \\
\hline & 一 & - & 0.0514 & 0.2056 & 0.286 & 0.457 & - & 0.97220 \\
\hline \multirow{7}{*}{ ThUO mixture } & 0.800 & 0.100 & - & - & - & - & 0.100 & 0.45345 \\
\hline & 0.700 & 0.200 & - & - & - & - & 0.100 & 0.71546 \\
\hline & 0.610 & 0.290 & - & - & - & - & 0.100 & 0.90719 \\
\hline & 0.600 & 0.300 & - & - & - & - & 0.100 & 0.92764 \\
\hline & 0.580 & 0.320 & - & - & - & - & 0.100 & 0.96123 \\
\hline & 0.570 & 0.330 & - & - & - & - & 0.100 & 0.97984 \\
\hline & 0.565 & 0.335 & - & - & - & - & 0.100 & 0.98751 \\
\hline
\end{tabular}

Bold indicates the maximum value in the calculations.

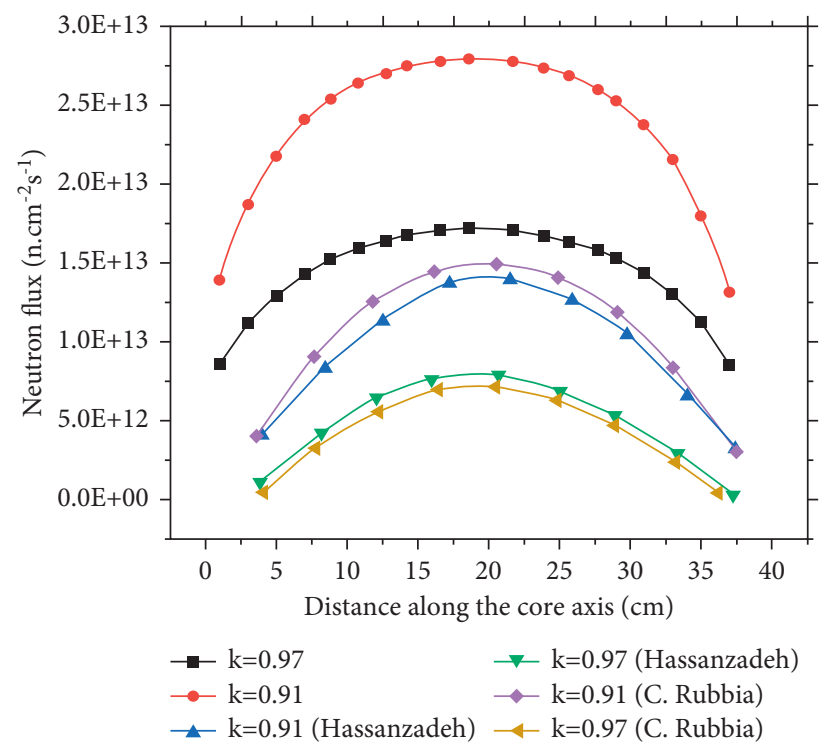

FIgURE 3: The axial distributions of the neutron flux with UZrH fuel mixture placed in the light water for the solid lead target.

times greater than that of $k$ equal to 0.91 and 0.97 , respectively.

The study results suggest that lead in solid or molten form should be considered for use in designing ADSR systems with the UZrH or ThUO fuel . The use of molten lead as both spallation neutron target and as a coolant with ThUO fuel results in a high neutron flux, and the design and operation of the ADSR system will be simpler. 


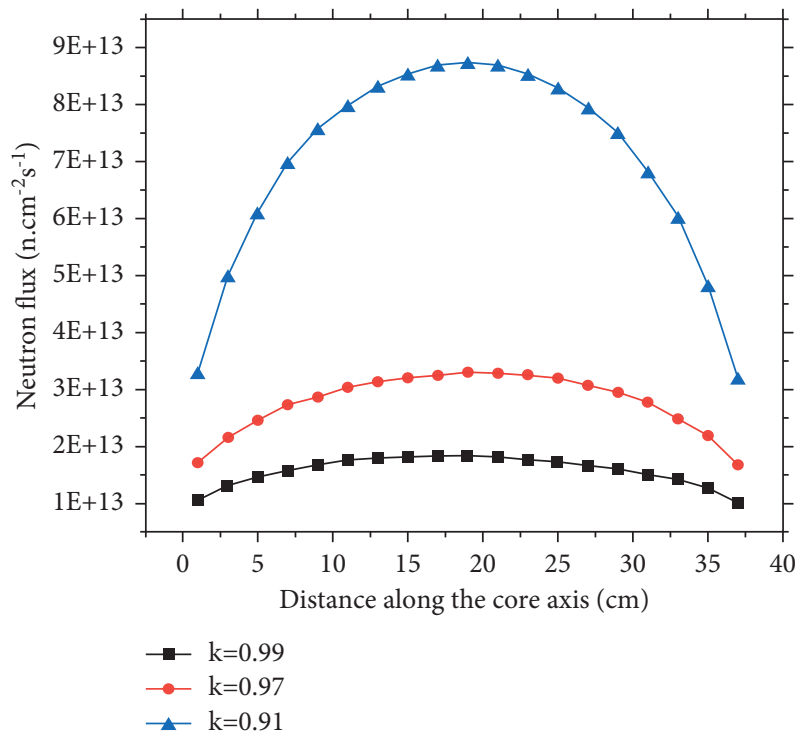

FIgUre 4: The axial distributions of the neutron flux with UZrH fuel mixture, placed in the molten lead as target and coolant.

TABle 4: Maximum and minimum neutron flux calculated for some configurations, coolant and target.

\begin{tabular}{|c|c|c|c|c|c|c|}
\hline \multirow[t]{2}{*}{$k$} & \multicolumn{2}{|c|}{$\begin{array}{c}\text { Case } 1 \\
\text { Neutron flux }\left(\mathrm{n} \cdot \mathrm{cm}^{-2} \mathrm{~s}^{-1}\right) \mathrm{UZrH}, \\
\text { molten lead (this work) }\end{array}$} & \multicolumn{2}{|c|}{$\begin{array}{c}\text { Case } 2 \\
\text { Neutron flux }\left(\mathrm{n} \cdot \mathrm{cm}^{-2} \mathrm{~s}^{-1}\right) \mathrm{UZrH} \text {, light } \\
\text { water, solid lead (this work) }\end{array}$} & \multicolumn{2}{|c|}{$\begin{array}{c}\text { Case } 3 \\
\text { Neutron flux }\left(\mathrm{n} \cdot \mathrm{cm}^{-2} \mathrm{~s}^{-1}\right) \mathrm{UZrH} \text {, light } \\
\text { water, tungsten (Hassanzadeh et al. [8]) }\end{array}$} \\
\hline & Maximum values & Minimum values & Maximum values & Minimum values & Maximum values & Minimum values \\
\hline 0.91 & $8.5 \times 10^{13}$ & $3.5 \times 10^{13}$ & $3.0 \times 10^{13}$ & $1.2 \times 10^{13}$ & $1.3 \times 10^{13}$ & $0.3 \times 10^{12}$ \\
\hline 0.97 & $3.4 \times 10^{13}$ & $1.6 \times 10^{13}$ & $1.8 \times 10^{13}$ & $0.8 \times 10^{13}$ & $0.6 \times 10^{13}$ & $0.2 \times 10^{12}$ \\
\hline 0.99 & $1.9 \times 10^{13}$ & $1.0 \times 10^{13}$ & - & - & - & - \\
\hline
\end{tabular}

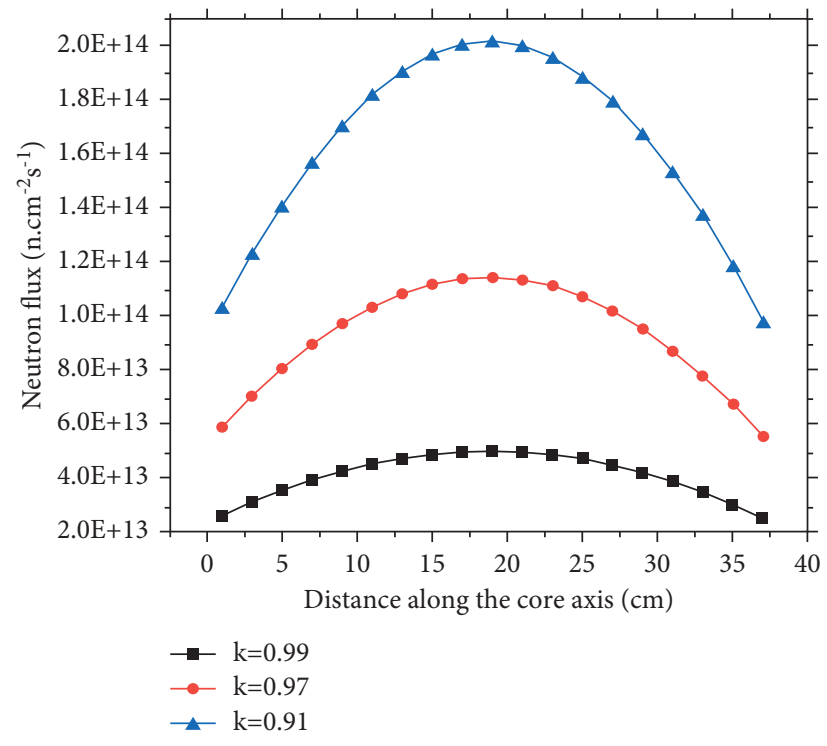

FIGURE 5: The axial distributions of neutron flux with ThUO fuel placed in molten lead.

TABLE 5: Neutron flux of ThUO and UZrH fuel in molten lead.

\begin{tabular}{cccccc}
\hline \multirow{2}{*}{$k$} & \multicolumn{2}{c}{ Neutron flux $\left(\mathrm{n} \cdot \mathrm{cm}^{-2} \mathrm{~s}^{-1}\right)($ ThUO, molten lead) } & \multicolumn{2}{c}{ Neutron flux $\left(\mathrm{n} \cdot \mathrm{cm}^{-2} \mathrm{~s}^{-1}\right)(\mathrm{UZrH}, \mathrm{molten}$ lead) } \\
& Maximum values & Minimum values & Average values & Maximum values & Minimum values \\
Average values \\
\hline 0.91 & $2.1 \times 10^{14}$ & $1.0 \times 10^{14}$ & $1.6 \times 10^{14}$ & $8.5 \times 10^{13}$ & $3.5 \times 10^{13}$ \\
0.97 & $1.1 \times 10^{14}$ & $0.6 \times 10^{14}$ & $0.9 \times 10^{14}$ & $3.5 \times 10^{13}$ & $1.6 \times 10^{13}$ \\
0.99 & $0.4 \times 10^{14}$ & $0.2 \times 10^{14}$ & $0.3 \times 10^{14}$ & $1.9 \times 10^{13}$ & $1.0 \times 10^{13}$ \\
\hline
\end{tabular}




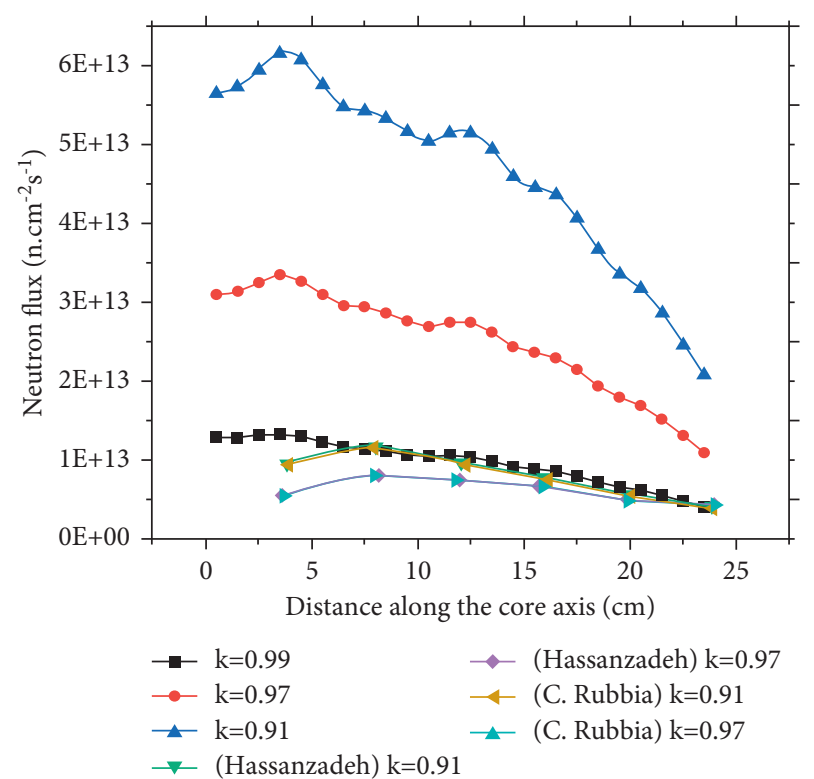

Figure 6: The radial distributions of the neutron flux in the case of ThUO mixture fuel, the molten lead as a target and coolant.

\section{Conclusions}

The basic structure of the TRIGA-Mark II reactor has been simulated using the MCNPX program. The basic neutron parameters have been calculated, such as the neutron yields, the effective neutron multiplication factor, and the axial and radial distribution of the neutron flux. The above study results have shown that, in the ADSR system, molten lead should be considered both as target and as a coolant. The possibility of using molten lead as both target and coolant, using thorium fuel in combination with uranium, is a very promising ADSR system.

The results show that the investigation of the neutronic parameters related to the fuel, target, and coolant plays an important role in the design and economical operation of an ADSR system.

\section{Data Availability}

The previous studies (and datasets) are cited at relevant places within the article as references.

\section{Conflicts of Interest}

The authors declare that there are no conflicts of interest regarding the publication of this paper.

\section{References}

[1] C. Rubbia, C. Roche, J. A. Rubio et al., Conceptual Design of a Fast Neutron Operated High Power Energy Amplifier (No. CERN-AT-95-44-ET), 1995.

[2] A. Asuncion-Astronomo, Ž. Štancar, T. Goričanec, and L. Snoj, "Computational design and characterization of a subcritical reactor assembly with TRIGA fuel," Nuclear Engineering and Technology, vol. 51, no. 2, pp. 337-344, 2019.
[3] H. R. Vega-Carrillo, I. R. Esparza-Garcia, and A. Sanchez, "Features of a subcritical nuclear reactor," Annals of Nuclear Energy, vol. 75, pp. 101-106, 2015.

[4] R. Henry, I. Tiselj, and L. Snoj, "Analysis of JSI TRIGA MARK II reactor physical parameters calculated with TRIPOLI and MCNP," Applied Radiation and Isotopes, vol. 97, pp. 140-148, 2015.

[5] M. Shukla, S. S. Desai, T. Roy et al., "Neutron spatial flux profile measurement in compact subcritical system using miniature neutron detectors," Nuclear Instruments and Methods in Physics Research Section A: Accelerators, Spectrometers, Detectors and Associated Equipment, vol. 772, pp. 118-123, 2015.

[6] A. Borio di Tigliole, A. Cammi, M. Clemenza, V. Memoli, L. Pattavina, and E. Previtali, "Benchmark evaluation of reactor critical parameters and neutron fluxes distributions at zero power for the TRIGA Mark II reactor of the University of Pavia using the Monte Carlo code MCNP," Progress in Nuclear Energy, vol. 52, no. 5, pp. 494-502, 2010.

[7] C. Rubbia, M. Carta, N. Burgio et al., "Preliminary neutronic analyses of the TRIGA-ADS demonstration facility," in Proceedings of the PHYSOR 2002 International Conference on the New Frontiers of Nuclear Technology, Seoul, Korea, October 2002.

[8] M. Hassanzadeh and S. A. H. Feghhi, "Sensitivity analysis of core neutronic parameters in accelerator driven subcritical reactors," Annals of Nuclear Energy, vol. 63, pp. 228-232, 2014.

[9] C. Rubbia, M. Carta, N. Burgio et al., "Neutronic analyses of the TRADE demonstration facility," in Nuclear Science and Engineeringvol. 148, no. 1, pp. 103-123, 2004.

[10] T. M. Tien and T. Q. Dung, "Calculation of the neutron flux distribution in the accelerator driven subcritical reactor with (Th-233U) O2 and (Th-235U) O2 mix fuel," Journal of Physics: Conference Series, vol. 1451, no. No. 1, Article ID 012009, 2020.

[11] H. G. Hughes, H. W. Egdorf, F. C. Gallmeier et al., MCNPX TMx 2.4.0, User's Manual-Version 2.4.0, Los Alamos National Laboratory, New Mexico, USA, 2002.

[12] https://www-nds.iaea.org/exfor/endf.htm. 